\title{
Behavioral flexibility in an invasive bird is independent of other behaviors
}

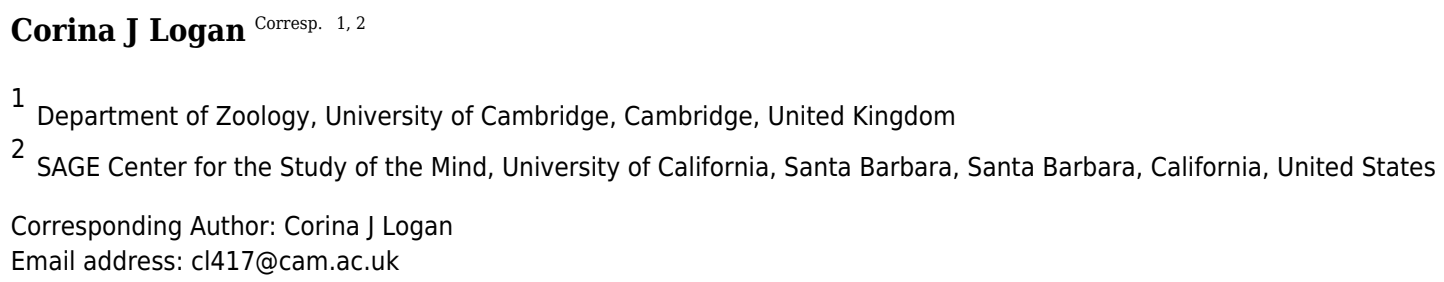

Behavioral flexibility is considered important for a species to adapt to environmental change. Behavioral flexibility relates to problem solving ability and speed in unpredictable ways, which leaves an open question of whether behavioral flexibility instead varies with differences in other behaviors, such as neophobia or exploration. If present, such correlations would mask which behavior causes individuals to vary. I investigated whether behavioral flexibility (reversal learning) performances were linked with other behaviors in great-tailed grackles, an invasive bird. I found that behavioral flexibility did not significantly correlate with neophobia, exploration, risk aversion, persistence, or motor diversity. This suggests that great-tailed grackle performance in behavioral flexibility tasks reflects a distinct source of individual variation. Maintaining multiple distinct sources of individual variation, and particularly variation in behavioral flexibility, may be a mechanism for coping with the diversity of novel elements in their environments and facilitating this species' invasion success. 


\title{
Behavioral flexibility in an invasive bird is independent of other behaviors
}

\author{
Corina J. Logan
}

SAGE Center for the Study of the Mind, University of California, Santa Barbara, CA 93106

U.S.A.

Current address: Department of Zoology, University of Cambridge, Cambridge CB2 3EJ U.K., c1417@cam.ac.uk

\section{BACKGROUND}

Behavioral flexibility, defined here as changing preferences according to changing circumstances based on learning (Logan 2016a,b), is considered a key factor involved in a species' ability to adapt to environmental change (Lefebvre et al. 1997, Griffin \& Guez 2014, Buckner 2015, Chow et al. 2016). However, it is not known how behavioral flexibility works: is it an independent trait, a problem solving ability, does it arise because of links with other behaviors such as neophilia and exploration, or is flexibility the result of an interaction between problem solving ability and other behaviors (see review in Griffin 2016)? There are a variety of ways to measure behavioral flexibility in an experimental context and all involve allowing an individual to learn about a task, which then changes after the individual becomes proficient. Individuals that adapt their behavior to these changing circumstances are considered to exhibit behavioral flexibility. Paradigms testing behavioral flexibility include tasks such as a multi-access box (Auersperg et al., 2011; Manrique, Völter \& Call, 2013), water tubes (Logan et al. 2014, Logan 2016a), and episodic-like memory and future planning experiments (Clayton \& Dickinson, 1998; Dally, Emery \& Clayton, 2006; Raby et al., 2007), however the most widely used measure is reversal learning (e.g., Bond et al. 2007, Tebbich et al. 2010, Boogert et al. 2011). Reversal learning involves learning to 
24 associate one option with a reward, which subsequently becomes incorrect when the reward is

25 moved to a different option, thus forcing the individual to reverse their preference to consistently

26 obtain the reward. The few studies that have investigated whether behavioral flexibility relates to

27 problem solving ability and speed have found that these traits do not covary in predictable ways

28 (Boogert et al. 2011, Griffin et al. 2013, Isden et al. 2013, Logan 2016a, Bebus et al. 2016). Two

29 studies found that faster learners were slower to reverse their preferences (Griffin et al. 2013,

30 Bebus et al. 2016), suggesting a speed-accuracy trade off that might depend on an individual's

31 ability to inhibit choosing the previously rewarded response (Manrique et al. 2013, Griffin \&

32 Guez 2014, Liu et al. 2016, but see Homberg et al. 2007). In contrast, four studies found no

33 correlations between reversal learning speed and problem solving ability or speed (Boogert et al.

34 2011, Isden et al. 2013, Shaw et al. 2015, Logan 2016a), which indicates that increased

35 flexibility did not lead to improvements in problem solving abilities. The latter results suggest

36 that flexibility could be a trait that varies across individuals independently of problem solving

37 ability, and all results considered together suggest that variation in flexibility might correlate

38 with other traits that were not measured in these studies.

39 This leaves an open question of whether behavioral flexibility varies with differences in

40 other behaviors such as exploration, neophobia, risk aversion, persistence, and motor diversity

41 (the number of different motor actions used to attempt to solve a novel problem). There is debate

42 about whether differences in behavior among individuals are linked to suites of correlated

43 behaviors or whether individual behaviors, such as behavioral flexibility, can vary independently

44 (Coppens et al. 2010, Cole et al. 2011, Sih \& Del Giudice 2012). Reversal learning is predicted

45 to fall on the fast-slow behavioral type continuum where fast individuals are exploratory, risk

46 seeking, and persistent with poor accuracy because of the speed with which they solve problems, 
47 whereas slow individuals are neophobic, risk averse, and more accurately solve problems (Sih \& Del Giudice 2012). Accordingly, slow individuals should be more behaviorally flexible because they might be less impulsive, that is, less likely to rush into a situation and persistently try a 50 particular solution, which gives them more time to survey the environment and attend to the relevant features of the situation (Sih \& Del Giudice 2012). Individuals that are more neophobic and less exploratory would also have more time to examine a situation before taking action, thus making them more likely to choose correctly when they do take action (Sih \& Del Giudice 54 2012).

These predictions are at odds with some evidence from the comparative cognition literature. In a multi-access box paradigm, keas (Nestor notabilis) were faster to explore and faster to learn more solutions, as well as faster to switch to trying new solutions when previously rewarded solutions stopped working than New Caledonian crows (Corvus moneduloides; Auersperg et al. 2011). In this case, a positive correlation between flexibility and exploration led to faster problem solving success, rather than the predicted negative correlation that would result from individuals inhibiting their actions and surveying the task. One reason for this difference could be due to it being an interspecies rather than an intraspecies comparison: differences between species are more likely to be larger and easier to detect than differences between individuals of the same species. Another reason for the disparity between predictions in the comparative cognition and individual differences literatures could come from defining terms differently or not at all. For example, persistence in attempting to solve a task is a measure of impulsivity, however persistence could be defined as the number of attempts directed to all parts of an apparatus or as the number of attempts directed at one part of the apparatus before trying a different part of the apparatus. As such, persistence could involve attention to function or not. 
70 The latter might be implied from the individual differences literature, while the former might be

71 implied from the comparative cognition literature. It is unclear whether definitional differences

72 might explain opposite predictions because it is only the recent merging of these two fields that

73 has brought about a need to clarify such definitions. Regardless of potential difficulties arising

74 from differences in definitions, if behavioral flexibility correlates with other behaviors, such

75 correlations could mask whether individuals vary in their behavioral flexibility because this trait

76 is independent or because this variation is caused by a correlated behavior (Herrmann et al. 2010,

77 Thornton \& Lukas 2012, Seed et al. 2012).

78 Results from the few studies that investigated the relationship between behavioral

79 flexibility and other behaviors are equivocal. Consistent with predictions, black-capped

80 chickadees (Poecile atricapillus) and great tits (Parus major) that were more flexible (faster to

81 reverse a previously learned preference) were slower to explore (Verbeek et al. 1994, Guillette et

82 al. 2011), and great tits that were more flexible (reversal learning) were more neophobic

83 (Verbeek et al. 1994). Two studies provided evidence inconsistent with the predictions that

84 behavioral flexibility will positively correlate with neophobia and negatively with exploration:

85 there were no correlations between behavioral flexibility (reversal learning) and neophobia or

86 exploration in Florida scrub jays (Aphelocoma coerulescens; Bebus et al. 2016), and also no

87 correlations with activity or boldness in wild cavies (Cavia aperea; Guenther et al. 2014a).

88 Given this mixed evidence, it is not yet clear whether behavioral flexibility is part of a suite of

89 correlated traits or a trait that varies independently across individuals.

90 Innovativeness, considered a subcategory of behavioral flexibility, was linked with the

91 number of motor actions used to try to solve a novel problem, but not with persistence or

92 neophobia in several bird species (Griffin et al. 2014, Diquelou et al. 2016, Griffin \& Diquelou 
93 2015). Innovativeness, defined as inventing new behaviors to solve novel problems or using

94 existing behaviors in new ways (Griffin \& Guez 2014), is distinct from behavioral flexibility. For

95 example, great-tailed grackles exhibit behavioral flexibility in two tests involving reversal

96 learning, showing that they are among the fastest bird species to both learn an initial preference

97 and to reverse this preference (Logan 2016a). However, grackles are not particularly inventive

98 when it comes to creating new behaviors to solve novel problems: they did not successfully

99 innovate string pulling or stick tool use, which are behaviors that many other bird species engage

100 in (Logan 2016b). While it is unknown how motor diversity interacts directly with behavioral

101 flexibility, the prediction is that these traits will positively correlate because increasing the

102 number of motor actions attempted could increase the probability and speed of finding a

103 successful solution to a novel problem (Diquelou et al. 2016).

104 To determine whether behavioral flexibility is related to a variety of behaviors in one

105 species, I investigated great-tailed grackles (Quiscalus mexicanus, family Icteridae, hereafter

106 referred to as grackles), a generalist forager (Skutch 1954, Johnson \& Peer 2001, Wehtje 2003)

107 that is behaviorally flexible (Logan 2016a). Grackles are a native invasive species (Peer 2011):

108 they have expanded their range north from Central America into North America by over 5500\%

109 over the course of 120 years following the expansion of human modified environments, which is

110 their preferred habitat (Wehtje 2003). Behavioral flexibility is hypothesized to be a mechanism

111 involved in successful species invasions (Sol \& Lefebvre 2000). Whereas grackles could have

112 expanded their range simply because of an increase in their suitable habitat, species differences

113 in traits that facilitate adapting to environmental change, such as diet, are additionally implicated

114 (Blackburn et al. 2009). Behavioral flexibility is one such trait and a better understanding of how

115 it works could have implications for managing species invasions. To better understand 
116 behavioral flexibility, I tested the hypothesis that individual variation in behavioral flexibility

117 correlates with variation in other behaviors on the fast-slow continuum.

118 I predicted that individuals that were more behaviorally flexible would also be the most

119 neophobic and risk averse, the least persistent and exploratory, and use more motor actions. I

120 quantified grackles' activity levels (exploration) when placed in a novel environment and also

121 measured the amount of time spent in the safest sections of the aviary (risk aversion). I measured

122 grackles' neophobic reactions to a novel object next to a food dish in comparison with controls

123 where only a food dish was present. Persistence and motor diversity were measured from videos

124 of a stick tool use experiment (Logan 2016b), where no bird successfully invented stick tool use.

125 Therefore, birds were never rewarded for their actions, which is important when measuring

126 persistence because a food reward could differentially influence persistence across individuals:

127 those who are better at the task would receive more food rewards, which might increase their 128 persistence in future trials.

\section{METHODS}

\section{Ethics}

132 This research was conducted in accordance with the following permits: U.S. Fish and Wildlife

133 Service (scientific collecting permit number MB76700A-0), U.S. Geological Survey Bird

134 Banding Laboratory (federal bird banding permit number 23872), California Department of Fish 135 and Wildlife (scientific collecting permit number SC-12306), and the Institutional Animal Care 136 and Use Committee at the University of California Santa Barbara (IACUC protocol numbers 860 137 and 860.1). 


\section{Subjects}

140 Eight adult great-tailed grackles (4 females and 4 males) were caught in the wild and held for 2-3

141 months in aviaries before being released back to the wild (see Logan 2016a for full details). Half

142 of the birds were caught in Santa Barbara, California in September 2014 and released in

143 December 2014 (Tequila, Margarita, Cerveza, and Michelada; batch 1) and the other half were

144 caught in January 2015 and released in March 2015 (Refresco, Horchata, Batido, Jugo; batch 2).

\section{Study Set Up}

147 Grackles were housed individually in aviaries (183 cm high by $119 \mathrm{~cm}$ wide by $236 \mathrm{~cm}$ long) at 148 the University of California Santa Barbara. Grackles had ad libitum access to water at all times, 149 and unrestricted amounts of food (Mazuri® Small Bird Food) for a minimum of 20 hrs per day.

150 On testing days, their main diet was removed for up to 4 hrs while they participated in

151 experiments and could eat bread or peanuts if successful. Apparatuses were placed on tables (60 $152 \mathrm{~cm}$ wide by $39 \mathrm{~cm}$ long) and rolled into each aviary for sessions (approximately 20 min per 153 session), which were visually isolated from other grackles and video recorded with a Nikon 154 D5100 camera on a tripod. Experimenters stood just outside the aviary door and in full view of 155 the grackles during the persistence and motor diversity sessions, which did not interfere with 156 behavior (i.e., they readily interacted with the apparatus) because they were habituated to 157 humans in the wild and in the aviary.

159 Statistical Analyses

160 Data were analyzed in R 3.2.1 (R Core Team 2015). For those tests that involved p-values, a 161 result was considered statistically significant when $p<0.05$. When multiple $p$-values were 
162 obtained for one experiment, a Bonferroni-Holm correction was applied to avoid obtaining false

163 positive results simply by conducting many tests on the same data.

164

165 Data Accessibility

166 Data are available at the KNB Data Repository (Logan 2016c;

167 https://knb.ecoinformatics.org/\#view/corina_logan.18.15). Behavioral flexibility data were

168 previously published and are available at KNB (Logan 2016d).

169

170 Videos

171 Clips of videos from each experiment are available at: https://youtu.be/4efJ2afatus.

172

173 Exploration and Risk Aversion

174 The exploration session lasted $60 \mathrm{~min}$, starting $30 \mathrm{~min}$ after a wild bird's release into the aviary,

175 a novel environment. The grackles' previous experience was always the same: they were

176 trapped, blood was collected, and colored rings put on their legs; they were transported to the

177 aviary in a cat carrier in a car, biometrics were taken, and then they were released into the aviary

178 where they were singly housed, given food and water, and the camera was set up outside their

179 door. The camera was restarted every $20 \mathrm{~min}$, otherwise experimenters were out of visual and 180 auditory contact when recording.

181 Exploration is measured in a number of different ways and I chose two measures for the

182 purposes of this study, which have been used to measure exploration in other species: the amount

183 of activity in a novel environment (exploration; e.g., Verbeek et al. 1994, Fox et al. 2009) and 
184 the amount of time spent in the safe areas of the novel environment (risk aversion; e.g., Lynn \&

185 Brown 2009, Lerman et al. 2012, Jolles et al. 2014).

186 Exploration: Videos were coded by Linnea Palmstrom to determine how often birds

187 moved between sections of the aviary. The aviary was invisibly sectioned into 5 areas with

188 sections 1 and 5 in the upper half of the aviary, where the perches were located, and sections 2-4

189 on the ground (Figure 1). Their exploration score was the number of times they moved from one

190 aviary section to another over the course of the 60 min session, which was an appropriate time

191 period (Montiglio et al. 2010) because an individual's activity level was ranked similarly

192 regardless of whether activity occurred in the first 5 min or over the whole session (Spearman's

193 rank correlation: $\mathrm{S}=31.43, \mathrm{p}=0.10$, $\mathrm{rho}=0.63, \mathrm{n}=8)$.

194 Risk aversion: I (invisibly) divided the aviary into safer versus riskier sections (Figure 1)

195 and used the percentage of time spent in sections 1-3 (the safer sections) as a measure of risk

196 aversion. The rear of the aviary was considered less risky because it was the farthest from the

197 door where the camera and other equipment were visible, while the ground and the perches in the

198 front of the aviary were more risky because these sections were next to the door and walking on

199 the ground is more dangerous than flying. Food and water were placed on the ground near the

200 door. The aviary was covered in tarpaulins on three sides (both sides and rear), while the side

201 with the door (front) and the ceiling were wire mesh that the bird could see through.

202

203 Neophobia

204 The neophobia sessions began on a grackle's sixth day in the aviary and involved three 10-min

205 trials with trials 1 and 3 serving as a way to quantify food motivation by placing a food bowl

206 alone on the table, while trial 2 had a novel object $2 \mathrm{~cm}$ to the right of the food bowl (as in 
207 Boogert et al. 2006). There were 2 min between trials. In all trials, the food bowl contained $1 / 4$ 208 of a peanut and the latency to land on the table and to feed was recorded as well as which object 209 was approached first in trial 2 (the food bowl or the novel object). Three novel objects were 210 presented in random order to each bird: a GoPro camera inside its clear waterproof case, a stone 211 dropping training apparatus (see Logan 2016a), and a colored U-tube apparatus (see Logan et al. 212 2016). The stone dropping training apparatus was a clear acrylic box ( $8.8 \mathrm{~cm}$ tall by $18 \mathrm{~cm}$ wide 213 by $11 \mathrm{~cm}$ deep) with a clear acrylic tube $(9 \mathrm{~cm}$ tall, outer diameter $=5 \mathrm{~cm})$ on top. The colored U214 tube apparatus was a box ( $8 \mathrm{~cm}$ tall by $40 \mathrm{~cm}$ wide by $30 \mathrm{~cm}$ deep) with a wooden frame covered 215 in cardboard and a clear acrylic top covered by colored paper. Two clear acrylic tubes (both 17 $216 \mathrm{~cm}$ tall, one with an outer diameter of $5.1 \mathrm{~cm}$ and the other $2.5 \mathrm{~cm}$ ) protruded from the center of 217 the box and were marked with colored tape at the top. If a grackle did not come to the table 218 within the $10 \mathrm{~min}$ period it received a trial duration of 601 seconds. The neophobia tests were 219 conducted on three consecutive days, with one novel object presented to the bird on each day.

220 Data were analyzed using the latency to land on the table rather than the latency to feed

221 because birds came to the table more often than they ate the food. The data were not normally 222 distributed (Anderson-Darling normality test: GoPro: $\mathrm{A}=3.08, \mathrm{p}<0.001$; stone dropping 223 apparatus: $\mathrm{A}=2.76, \mathrm{p}<0.001$; U-tube: $\mathrm{A}=2.46, \mathrm{p}<0.001)$. Therefore, non-parametric paired 224 Wilcoxon signed rank tests with continuity corrections were conducted to determine whether 225 latencies in control trials (averaged) differed from novel object trials. Neophobia scores were 226 obtained for each novel object and summed for an overall score per individual. Scores were 227 calculated by subtracting the latency to land on the table during the novel object trials (trial 2) 228 from the average latency during control trials (trials 1 and 3). Positive scores indicate less 229 neophobia while negative scores indicate more neophobia. Repeatability of individual neophobic 
230 responses across contexts was measured using Spearman's rank correlations to determine

231 whether grackles maintained similar neophobia ranks with each of the three novel objects.

232

233 Persistence and Motor Diversity

234 Persistence and motor diversity were calculated as in Griffin \& Diquelou (2015). Persistence

235 was calculated as the attempt rate: the number of times a bird came to the table or interacted with

236 (touched) the apparatus or stick across 21 trials of a stick tool use experiment (105 min/bird;

237 Logan 2016b). Motor diversity was calculated by counting the number of different motor actions

238 (described in Table 3) performed per individual across the 21 trials of the experiment. Videos

239 were watched from trials 1 to 21 and behaviors from the ethogram (Table 3 ) were coded at their

240 first observation.

241 The stick tool use experiment involved an apparatus with a wooden base and rear with

242 clear cast acrylic walls providing a narrow gap at the front and top of the apparatus to insert a

243 stick and retrieve a piece of bread (Logan 2016b). Birds were given 215 min trials to innovate

244 tool use: first, 3 trials with the stick placed on the table next to the apparatus, then 3 trials with

245 the stick inserted into the apparatus, and finally 15 trials with the stick inserted in the apparatus

246 and tool use demonstrated by the human experimenter.

248 Measure of Behavioral Flexibility

249 These grackles were previously tested on reversal learning of a color discrimination task

250 consisting of a gold tube and a silver tube placed on the table at the same time with one color

251 containing hidden food and the opportunity to make only one choice per trial (Logan 2016a).

252 Grackles initially learned to search for food hidden in the gold tube and, once proficient, the food 
253 was switched to the silver tube and the number of trials required to reach proficiency was

254 assessed. Behavioral flexibility scores were calculated as the number of trials to reverse a color

255 preference minus the number of trials needed to initially learn the color preference (Table 4).

256 Proficiency in the initial discrimination and reversal was demonstrated if individuals chose

257 correctly in at least 17 of the most recent 20 trials with at least 8 or 9 trials correct per set of 10 . I

258 then investigated whether relationships between individual variation in behavioral flexibility and 259 exploration, risk aversion, neophobia, persistence, and motor diversity conformed to predictions.

\section{General Analyses}

262 I determined whether behavioral flexibility (response variable: behavioral flexibility score)

263 negatively correlated with exploration and persistence while examining whether batch had an 264 effect (explanatory variables) using a Generalized Linear Model (GLM; MCMCglmm function, 265 MCMCglmm package; Hadfield 2014) with a Poisson distribution and log link using 13000 266 iterations with a thinning interval of 10 and a burnin of 3000. The GLM showed acceptable 267 convergence (lag time autocorrelation values were $<0.01$; Hadfield 2010). Risk aversion and 268 motor diversity were excluded from the analysis because they significantly covaried with 269 exploration and persistence, respectively. A Spearman's rank correlation was used to investigate 270 the relationship between behavioral flexibility and neophobia because residuals were not 271 normally distributed.

272 Given the small sample size ( $\mathrm{n}=7$ for behavioral flexibility scores), I conducted a further 273 analysis to determine whether GLM results were likely to be reliable given the data (Burnham \& 274 Anderson 2002). I compared the Akaike weights (range: 0-1, the sum of all model weights 275 equals 1; Akaike 1981) between the test model (above) and a null model (behavioral flexibility 
276 score as the response variable and 1 as the explanatory variable) using the dredge function in the

277 MuMIN package (Bates et al. 2011). If the best fitting model has a high Akaike weight $(>0.89$;

278 Burnham \& Anderson 2002), then it indicates that the results are likely given the data. The null

279 model was strongly supported with an Akaike weight of 0.92 , thus indicating the results are

280 reliable even with a small sample size.

281

282 Interobserver Reliability

283 Linnea Palmstrom coded the exploration/risk aversion videos, I coded neophobia videos, and

284 Katherine Lister coded persistence and I coded motor diversity from videos of a tool use 285 experiment (in Logan 2016b). To measure interobserver reliability, I randomly chose $21 \%$ of the 286 videos using www.random.org and had a coder who was naïve to the hypotheses (Katharina 287 Brecht) recode their exploration (from which measures of risk aversion are calculated), 288 persistence, and neophobia. I randomly chose 3 of the 8 birds using www.random.org and had 289 Katharina recode their motor diversity (36\% of the videos). A higher percentage of motor 290 diversity videos were recoded because agreement determinations were based on the total number 291 of motor actions per bird, which required watching all videos for an individual. There was 292 agreement between Katharina and all other observers for each study: exploration (intraclass 293 correlation coefficient $(\mathrm{ICC})=0.998,95 \%$ confidence intervals $(\mathrm{CI})=0.98-1.00$ ), neophobia 294 (ICC $=0.87,95 \% \mathrm{CI}=0.67-0.95$ ), persistence (land on table: $\mathrm{ICC}=0.79,95 \% \mathrm{CI}=0.49-0.93$; 295 interact with apparatus: $\mathrm{ICC}=1.00,95 \% \mathrm{CI}=0.999-1.00$; interact with stick: $\mathrm{ICC}=1.00,95 \%$ $296 \mathrm{CI}=\mathrm{NA})$, and motor diversity $(\mathrm{ICC}=0.71,95 \% \mathrm{CI}=0.54-0.82$; ICCs calculated using $\mathrm{R}$ package: 297 irr, function: icc, Gamer et al. 2012). 


\section{RESULTS}

300 Exploration and Risk Aversion

301 Exploration and risk aversion were significantly negatively correlated, indicating that these two

302 variables might measure opposite ends of the same behavior or an unmeasured behavior might

303 correlate with both and explain their relationship (Spearman's rank correlation: S=159.45,

$304 \mathrm{p}=0.002$, rho $=-0.90, \mathrm{n}=8$ ). To eliminate covariance between explanatory variables, I used

305 exploration to represent this behavior in further analyses (see General Analyses section).

306 Exploration: Grackles varied in how many times they changed sections across the 60

307 min session (0-163), with Refresco having no section changes and Jugo having the most (Table

308 1). They also varied in the total number of sections they visited during the session (1-5; Table 1).

309 Risk aversion: Grackles varied in how much time they spent in the safest sections of the

310 aviary with Batido spending the least time and Refresco the most (Table 1). All grackles (except

311 Refresco) moved through other sections of the aviary and they varied in how much time they

312 spent in sections 4 and 5 (Table 1).

313

314 Neophobia

315 There were no significant differences between the latency to land on the table in controls (pre

316 [trial 1] or post [trial 3] novel object trials) versus novel object trials (trial 2) (Wilcoxon tests

317 with Bonferroni-Holm corrected p-values: GoPro: trials 1-2 V=21, p=1.00, 95\% confidence

318 interval $=-283-267$, trials $2-3 \mathrm{~V}=8, \mathrm{p}=1.00,90 \% \mathrm{CI}=-427-277.5$; stone dropping apparatus: trials

$3191-2 \mathrm{~V}=7, \mathrm{p}=1.00,80 \% \mathrm{CI}=-369-338$, trials $2-3 \mathrm{~V}=0, \mathrm{p}=0.54,80 \% \mathrm{CI}=-455-(-41)$; U-tube: trials

$3201-2 \mathrm{~V}=1, \mathrm{p}=0.88,80 \% \mathrm{CI}=-481-(-85)$, trials $2-3 \mathrm{~V}=1, \mathrm{p}=0.88,80 \% \mathrm{CI}=-507-(-190.5))$. Refresco

321 and Margarita were overall less neophobic than the other grackles, and Horchata was the most 
322 neophobic (Table 2). There were many trials in which the bird did not come to the table.

323 However, this did not usually appear to be due to neophobia because it happened in many control

324 trials as well as novel object trials, indicating that it might have been due to a lack of motivation

325 to eat or explore the object.

326 There was no individual repeatability of neophobia scores across contexts (Spearman's

327 rank correlation with Bonferroni-Holm corrected p-values: GoPro vs. stone dropping apparatus:

$328 \mathrm{~S}=79.21, \mathrm{p}=1.00, \mathrm{rho}=-0.41$, GoPro vs. U-tube: $\mathrm{S}=56.00, \mathrm{p}=1.00$, rho=0.00; U-tube vs. stone

329 dropping apparatus: $\mathrm{S}=20.68, \mathrm{p}=0.88$, rho $=0.63$ ).

330

331 Persistence and Motor Diversity

332 Grackles varied in the number of motor actions they used (1-15) and in how persistent they were

333 (18-4047 total number of times a bird landed on the table, touched the apparatus, or touched the

334 stick; Table 4). A post-hoc analysis indicated that these two variables were significantly

335 positively correlated, indicating that they could have measured the same behavior or have been

336 caused by another, unmeasured variable (Spearman's rank correlation: $\mathrm{S}=8.55, \mathrm{p}=0.002$,

$337 \mathrm{rho}=0.90, \mathrm{n}=8$ ). Therefore, only persistence was used in further analyses (see General Analyses

338 section).

340 Does behavioral flexibility positively correlate with motor diversity and risk aversion, and

341 negatively with exploration and persistence?

342 Birds that were more flexible (i.e., faster to reverse a preference: number of trials to reverse a

343 preference minus the number of trials to initially learn the preference) did not have higher

344 exploration scores, they were not more persistent, and there were no batch effects (Figure 2, 
345 Supplementary Table S1). There were no significant correlations between flexibility and

346 exploration or persistence, indicating that results did not provide evidence for the predicted

347 negative correlations.

348 Risk aversion and motor diversity significantly covaried with exploration and persistence,

349 respectively, and these relationships were investigated further. I confirmed that the relationship

350 between these variables and behavioral flexibility was the same as their collinear variables with

351 an additional GLM. This GLM was the same as above, except the explanatory factors were

352 motor diversity, risk aversion and batch. As above, flexibility did not correlate with risk aversion

353 or motor diversity (Figure 2, Supplementary Table S2).

354

355 Does behavioral flexibility positively correlate with neophobia?

356 Grackles that were more flexible (i.e., faster to reverse a preference) did not have lower 357 neophobia scores, which would indicate more neophobia. There was no significant correlation 358 between behavioral flexibility scores and neophobia (Figure 2; Spearman's rank correlation: $359 \mathrm{~S}=92, \mathrm{p}=0.12$, rho=-0.65).

360

361 DISCUSSION

362 Exploration and Risk Aversion

363 The exploration and risk aversion scores significantly negatively correlated with each other,

364 indicating they might have measured opposite ends of the same behavior. While risk aversion

365 scores could have been confounded by the placement of food and water in a risky section, which

366 might attract birds to this area, they spent only $0-14 \%$ of their time in the section with the food 
367 and water (section 4). This indicates that they behaved more according to the prediction that this

368 section would be treated as risky even when an attractor was present.

369 I question whether the measure of exploration actually measured exploration in this

370 species. A bird that is stressed tends to fly back and forth in an aviary, which is not an indicator

371 of exploration, but would be interpreted as such according to the section change measure of

372 exploration. In this study, Jugo mostly flew back and forth between the perches near the top of

373 the aviary while looking up and out of the aviary and not attending to the environment within the

374 aviary. In contrast, Horchata also had many section changes, but she usually walked calmly on

375 the ground, thus perhaps in her case this measure of exploration was appropriate. Therefore, at

376 the species level, activity levels are likely not a good indicator of exploration behavior. Indeed, a

377 distinction is made between forced exploration, where an individual is placed in a novel

378 environment, and voluntary exploration, where an individual in a familiar environment is

379 provided with the opportunity to enter a novel environment (Guenther et al. 2014b). A study on

380 wild guinea pigs (Cavia aperea) found that these two variations of exploration measure different

381 behaviors: forced and voluntary exploration activity did not correlate in juveniles or adults

382 (Guenther et al. 2014b).

383 Voluntary exploration would likely be a more accurate measure of actual exploratory

384 behavior in grackles, which could also involve voluntary exploration of a novel object in a

385 familiar environment. Such a measure is also called a neophilia test where a novel object is

386 placed in a familiar aviary in the presence of (but not next to) their regular food source to

387 determine how soon the bird approaches and interacts with the apparatus and for how long (as in

388 Mettke-Hoffman et al. 2002). This kind of test would also likely more directly relate to how

389 grackles have expanded their range so rapidly: rather than exploring novel environments, 
390 grackles are more likely to have successfully expanded their range by exploring novel objects.

391 Grackles have not necessarily needed to adapt to novel environments during their range

392 expansion because it coincided with an increase in their suitable (human-managed) habitat

393 (Wehtje 2003). Exploration is more likely to have played a role in exploiting novel objects in

394 their environment because humans throw away products that may be novel to grackles (e.g., egg

395 cartons, yogurt cups) and design new potential food sources (e.g., dumpsters) where food is not

396 necessarily obvious, therefore the objects must be explored to determine whether they contain

397 food.

398

399 Neophobia

400 Grackles were not generally neophobic because no significant differences were found between 401 controls and novel object trials in the latency to land on the table. Indeed, the GoPro camera, 402 which was also the smallest of the novel objects, appeared to attract their attention more than the 403 food. Comparing grackles with other species that have been tested using a similar design, it 404 appears that they are less neophobic than starlings (Sturnus vulgaris; Boogert et al. 2006), blue 405 tits (Cyanistes caeruleus; Herborn et al. 2010), Japanese quail (Coturnix japonica; Zimmer et al. 406 2013), Chimango caracaras (Milvago chimango; Biondi et al. 2010), European greenfinches

407 (Carduelis chloris; Herborn et al. 2011), Indian mynas (Sol et al. 2012, Griffin \& Diquelou 408 2015), and mountain chickadees (Poecile gambeli; Kozlovsky et al. 2015), and that they have 409 similar levels of neophobia as noisy miners (Manorina melanocephala; Griffin \& Diquelou 410 2015) and a different group of mountain chickadees (Fox et al. 2009).

411

\section{Persistence and Motor Diversity}


413 The persistence and motor diversity scores significantly correlated with each other, indicating

414 they might have measured the same behavior or have been caused by another, unmeasured

415 variable. This suggests that the longer a bird persists in attempting to solve a task, the more

416 likely it is to use a wider variety of motor actions. Therefore, it is likely that individuals that used

417 few motor actions would likely have used more if they were perhaps more motivated to interact

418 with the task. Measuring persistence and motor diversity in a variety of contexts could address

419 this potential issue and clarify whether these variables actually do covary on a task that all

420 individuals persist on. These results are different from findings using a similar experimental

421 design on Indian mynas and noisy miners where motor diversity differed between species, but

422 persistence did not, thus indicating these were two separate behaviors (Griffin \& Diquelou

423 2015). However, birds in Griffin \& Diquelou (2015) could receive food rewards from the

424 apparatus if successful (i.e., at the end of each bout of persistence) and such positive

425 reinforcement for persisting could have increased persistence for successful individuals in 426 subsequent trials.

427

428 Behavioral Flexibility

429 Contrary to predictions, behavioral flexibility did not correlate with exploration, neophobia, risk 430 aversion, persistence, or motor diversity. The small sample size might have limited my ability to 431 detect significant correlations; however the behavior of the models suggested this was not the 432 case. It is perhaps not surprising that behavioral flexibility did not correlate with neophobia (the 433 only behavior I was able to obtain repeatability measures from) because neophobia was not 434 expressed consistently across contexts. This could indicate a further source of individual 435 variation in grackles or it could result from the inability of the method to accurately measure 
436 neophobia in this species. The latter highlights the importance of conducting repeatability tests

437 when attempting to understand how two variables correlate because two unpredictable variables

438 (behavioral flexibility and neophobia) would not likely correlate with each other. These results

439 are similar to results from Florida scrub jays where behavioral flexibility (reversal learning) did

440 not correlate with neophobia or exploration (Bebus et al. 2016). The few studies that investigate

441 the relationship between behavioral flexibility and other behaviors either show relationships

442 opposite to predictions (Verbeek et al. 1994, Guillette et al. 2011) or show no correlations (this

443 study, Bebus et al. 2016). One prediction was supported in only one test: reversal learning speed

444 negatively correlated with neophobia (Verbeek et al. 1994). This accumulating evidence suggests

445 the need to reconsider the basis for hypotheses linking other behaviors with behavioral

446 flexibility.

447

448 CONCLUSIONS

449 Traditionally, behavioral flexibility is thought of as a cognitive ability (see review in

450 Shettleworth 2010) and is considered as such in hypotheses linking it with other behaviors (Sih

451 \& Del Giudice 2012, Guenther et al. 2013). However, mixed results, with none conforming to

452 predictions, from grackles, keas and New Caledonian crows question this assumption. Grackles

453 lacked correlations between behavioral flexibility and problem solving ability and speed, and

454 individuals that were behaviorally flexible in one type of test were not necessarily flexible in a

455 different type of test (Logan 2016a). The more exploratory keas were more behaviorally flexible

456 on a multi-access box and faster to innovate new solutions to novel problems than New

457 Caledonian crows (Auersperg et al. 2011). These mixed results indicate a need to look beyond

458 cognitive and behavioral measures that might correlate with behavioral flexibility and investigate 
459 relationships with factors such as physiology and genetics. For example, grackles that are in

460 better phenotypic condition (e.g., have better immunity) might have the capacity to be more

461 behaviorally flexible than individuals in worse phenotypic condition. Non-behavioral, non-

462 cognitive individual factors have yet to be measured in relation to behavioral flexibility.

463 Considering behavioral flexibility in this more integrated way could allow experimenters to

464 manipulate this elusive trait to understand what it is and how it works.

465 Though the sample size is small, these results provide further support that behavioral

466 flexibility represents a distinct axis of individual variation in behavior. Behaviors that do not

467 correlate with each other are suggested to represent "inherent individual differences" in each of

468 the traits measured (Cole et al. 2011, p. 495). For example, great tit problem solving ability did

469 not correlate with body condition, neophobia, or exploration; therefore problem solving was

470 considered its own behavior that varies across individuals rather than varying due to links with

471 other individual traits (Cole et al. 2011). The methods used to measure neophobia and

472 exploration in grackles might not have accurately represented these behaviors, therefore further

473 investigations using different methods that are validated measures of these behaviors in grackles

474 should be explored before entirely ruling out correlations with behavioral flexibility. Previous

475 research on grackles and other species has shown that behavioral flexibility is independent from

476 innovativeness (Logan 2016b), problem solving ability and speed (Boogert et al. 2011, Isden et

477 al. 2013, Logan 2016a), or that it negatively correlates with problem solving speed (Griffin et al.

478 2013). The majority of evidence so far indicates that individual variation in behavioral flexibility

479 is not confounded with other behaviors, although two alternative hypotheses cannot yet be ruled

480 out: the behaviors might not have been measured with enough consistency across studies to

481 directly compare the results, or the behaviors are not repeatable enough within individuals to 
482 reliably covary with each other. Further research is needed to distinguish which hypothesis is 483 supported.

484 It could be adaptive for invasive species, such as the grackle, to maintain many 485 independent axes of individual variation and, in particular, variation in behavioral flexibility. 486 Indeed, Western bluebirds rely on existing intrapopulation variation when expanding their range 487 (Duckworth 2008). While Western bluebirds rely on variation in dispersal strategies, grackles 488 may rely on maintaining individual variation in behavioral flexibility, which could allow them to more quickly adapt to changing or unpredictable environments.

490

\section{FUTURE DIRECTIONS}

492 Future research investigating neophobia, exploration, persistence and motor diversity in this 493 species would benefit from a larger sample size, replicability of results from multiple groups, and

494 finding measures that are repeatable within individuals to determine the reliability of these 495 conclusions. Incorporating the use of a factor analysis would help determine whether correlated 496 explanatory variables measure distinct behaviors or arise from unmeasured correlated variables.

497 Investigating each variable using multiple methods will facilitate an understanding of which 498 methods actually measure the behaviors of interest.

ACKNOWLEDGEMENTS

501 I am grateful to Linnea Palmstrom for coding the exploration videos; Katherine Lister for coding

502 the persistence videos; Katharina Brecht for coding all videos for interobserver reliability

503 analyses; Luisa Bergeron, Christin Palmstrom, Linnea Palmstrom, and Michelle Gertsvolf for

504 trapping and aviary assistance; Steve Rothstein for use of the aviaries; Joe Jablonski for making 
505 the cast acrylic apparatuses; Jill Zachary and Kathy Frye at Santa Barbara City Parks and

506 Recreation for use of the Andree Clark Bird Refuge and East Beach Park; Estelle Sandhaus and

507 Chris Briggs at the Santa Barbara Zoo for access to wild grackles; Dieter Lukas, Ted Bergstrom, 508 and Carl Bergstrom for discussions; and Alecia Carter for analysis and manuscript feedback.

510 REFERENCES

511 Akaike H. 1981. Likelihood of a model and information criteria. Journal of Econometrics 16:314 doi:10.1016/0304-4076(81)90071-3

513 Auersperg AMI, von Bayern AMP, Gajdon GK, Huber L, Kacelnik A. 2011. Flexibility in 514 problem solving and tool use of kea and New Caledonian crows in a multi access box paradigm. PLoS ONE 6:e20231 doi:10.1371/journal.pone.0020231

Bates D, Maechler M, Bolker B. 2011. lme4: linear mixed-effects models using S4 classes. R package version 0.999375-42. Available at http:// CRAN.R-project.org/ package=lme4 (accessed 12 January 2016).

Bebus SE, Small TW, Jones BC, Elderbrock EK, Schoech SJ. 2016. Associative learning is inversely related to reversal learning and varies with nestling corticosterone exposure. Animal Behaviour 111:251-260 doi:10.1016/j.anbehav.2015.10.027.

Biondi LM, Bó MS, Vassallo AI. 2010. Inter-individual and age differences in exploration, neophobia and problem-solving ability in a Neotropical raptor (Milvago chimango). Animal Cognition 13:701-710 doi:10.1007/s10071-010-0319-8

Blackburn TM, Cassey P, Lockwood JL. 2009. The role of species traits in the establishment success of exotic birds. Global Change Biology 15:2852-2860 doi:10.1111/j.13652486.2008.01841.x 
528 Boogert NJ, Reader, SM, Laland KN. 2006. The relation between social rank, neophobia and

529 individual learning in starlings. Animal Behaviour 72:1229-1239

$530 \quad$ doi:10.1016/j.anbehav.2006.02.021

531 Boogert NJ, Anderson RC, Peters S, Searcy WA, Nowicki S. 2011. Song repertoire size in male song sparrows correlates with detour reaching, but not with other cognitive measures. Animal Behaviour 81:1209-1216 doi:10.1016/j.anbehav.2011.03.004

Buckner C. 2013. A property cluster theory of cognition. Philosophical Psychology 28:307-336 doi: $10.1080 / 09515089.2013 .843274$

Burnham KP, Anderson DR. 2002. Model selection and multimodel inference: a practical information- theoretic approach, 2nd edn. New York, NY: Springer. flexibility and learning in problem-solving efficiency. Animal Behaviour 112:273-283 doi: 10.1016/j.anbehav.2015.11.014

Clayton NS, Dickinson A. 1998. Episodic-like memory during cache recovery by scrub jays. Nature 395:272-274 doi:10.1038/26216

Cole EF, Cram DL, Quinn JL. 2011. Individual variation in spontaneous problem-solving performance among wild great tits. Animal Behaviour 81:491-498 doi:10.1016/j.anbehav.2010.11.025

Dally JM, Emery NJ, Clayton NS. 2006. Food-caching western scrub-jays keep track of who was watching when. Science 312:1662-1665 doi:10.1126/science.1126539

Diquelou MC, Griffin AS, Sol D. 2016. The role of motor diversity in foraging innovations: a cross-species comparison in urban birds. Behavioral Ecology 27:584-591 doi:10.1093/beheco/arv190 
551 Duckworth RA. 2008. Adaptive dispersal strategies and the dynamics of a range expansion. The

552

553

554

555

556

557

558

559

560

561

562

563

564

565

566

567

568

569

570

571

572 American Naturalist 172:S4-S17 doi:10.1086/588289

Fox RA, Ladage LD, Roth TC, Pravosudov VV. 2009. Behavioural profile predicts dominance status in mountain chickadees, Poecile gambeli. Animal Behaviour 77:1441-1448 doi:10.1016/j.anbehav.2009.02.022

Gamer M, Lemon J, Fellows I, Singh P. 2012. Various coefficients of interrater reliability and agreement. R Package. URL: http://www.r-project.org Accessed April 2016.

Griffin AS. 2016. Innova- tiveness as an emergent property: a new alignment of comparative and experimental research on animal innovation. Philosophical Transactions of the Royal Society B 371:20150544 doi:10.1098/rstb.2015.0544

Griffin AS, Diquelou MC. 2015. Innovative problem solving in birds: a cross-species comparison of two highly successful passerines. Animal Behaviour 100:84-94 10.1016/j.anbehav.2014.11.012

Griffin AS, Diquelou M, Perea M. 2014. Innovative problem solving in birds: a key role of motor diversity. Animal Behaviour 92:221-227 doi: 10.1016/j.anbehav.2014.04.009

Griffin AS, Guez D. 2014. Innovation and problem solving: a review of common mechanisms. Behavioural Processes 109:121-134 doi:10.1016/j.beproc.2014.08.027

Griffin AS, Guez D, Lermite F, Patience M. 2013. Tracking changing environments: Innovators are fast, but not flexible learners. PLoS ONE 8:e84907 doi:10.1371/journal.pone.0084907

Guenther A, Trillmich F. 2013. Photoperiod influences the behavioral and physiological phenotype during ontogeny. Behavioral Ecology 24:402-411 doi: 10.1093/beheco/ars177 
573 Guenther A, Brust V, Dersen M, Trillmich F. 2014a. Learning and personality types are

574 related in cavies (Cavia aperea). Journal of Comparative Psychology 128:74-81

575 doi:10.1037/a0033678

576 Guenther A, Finkemeier MA, Trillmich F. 2014b. The ontogeny of personality in the wild guinea pig. Animal Behaviour 90:131-139 doi:10.1016/j.anbehav.2014.01.032

578

579

580

581

582

583

584

585

586

587

588

589

590

591

592

593

594

595

Guillette LM, Reddon AR, Hoeschele M, Sturdy CB. 2011. Sometimes slower is better: slowexploring birds are more sensitive to changes in a vocal discrimination task. Proceedings of the Royal Society of London B 278:767-773 doi:10.1098/rspb.2010.1669

Hadfield J. 2010. MCMCglmm: Markov chain Monte Carlo methods for generalised linear mixed models. http://citeseerx.ist.psu.edu/viewdoc/download;jsessionid=E395FF7367BF580D916E465F 55302C60?doi=10.1.1.160.5098\&rep=rep1\&type=pdf Accessed 1 Jan 2016

Hadfield J. 2014. MCMCglmm: MCMC generalised linear mixed models. R package. https://cran.r-project.org/web/packages/MCMCglmm/index.html Accessed 1 Jan 2016

Herborn KA, Macleod R, Miles WT, Schofield AN, Alexander L, Arnold KE. 2010. Personality in captivity reflects personality in the wild. Animal Behaviour 79:835-843. doi:10.1016/j.anbehav.20 09.12.026

Herborn KA, Coffey J, Larcombe SD, Alexander L, Arnold KE. 2011. Oxidative profile varies with personality in European greenfinches. Journal of Experimental Biology 214:1732-1739 doi:10.1242/jeb.051383

Herrmann E, Hernández-Lloreda MV, Call J, Hare B, Tomasello M. 2010. The structure of individual differences in the cognitive abilities of children and chimpanzees. Psychological Science 21:102-110 doi:10.1177/0956797609356511 
596 Homberg JR, Pattij T, Janssen MC, Ronken E, De Boer SF, Schoffelmeer AN, Cuppen E.

597 2007. Serotonin transporter deficiency in rats improves inhibitory control but not

598 behavioural flexibility. European Journal of Neuroscience 26:2066-2073.

599 Isden J, Panayi C, Dingle C, Madden J. 2013. Performance in cognitive and problem-solving

600 tasks in male spotted bowerbirds does not correlate with mating success. Animal

601 Behaviour 86:829-838 doi:10.1016/j.anbehav.2013.07.024

602 Johnson K, Peer BD. 2001. Great-tailed grackle (Quiscalus mexicanus). In The birds of North

603 America online (ed. A Poole). Ithaca, NY: Cornell Lab of Ornithology.

604 Jolles JW, Fleetwood-Wilson A, Nakayama S, Stumpe MC, Johnstone RA, Manica A. 2014.

605 The role of previous social experience on risk-taking and leadership in three-spined

606 sticklebacks. Behavioral Ecology 25:1395-1401 doi:10.1093/beheco/aru146

607 Kozlovsky DY, Branch CL, Pravosudov VV. 2015. Problem-solving ability and response to

608 novelty in mountain chickadees (Poecile gambeli) from different elevations. Behavioral

$609 \quad$ Ecology and Sociobiology 69:635-643 doi:10.1007/s00265-015-1874-4

610 Lefebvre L, Whittle P, Lascaris E, Finkelstein A. 1997. Feeding innovations and forebrain

611 size in birds. Animal Behaviour 53:549-560 doi:10.1006/anbe.1996.0330

612 Lerman SB, Warren PS, Gan H, Shochat E 2012. Linking foraging decisions to residential

613 yard bird composition. PLoS ONE 7:e43497. doi:10.1371/ journal.pone.0043497

614 Liu Y, Day LB, Summers K, Burmeister SS. 2016. Learning to learn: advanced behavioural

615 flexibility in a poison frog. Animal Behaviour 111:167-172.

616 doi:10.1016/j.anbehav.2015.10.018

617 Logan CJ. 2016a. Behavioral flexibility and problem solving in an invasive bird. PeerJ 3:e1975.

618 doi:10.7717/peerj.1975 
619 Logan CJ. 2016b (in press). How far will a behaviourally flexible invasive bird go to innovate?

$620 \quad$ Royal Society Open Science. doi:10.1098/rsos.160247

621 Logan C. 2016c. Great-tailed grackle neophobia, persistence, exploration, risk aversion, motor

622 diversity, interobserver reliability data and R code, Santa Barbara, CA USA 2014-2015.

623 KNB Data Repository. https://knb.ecoinformatics.org/\#view/corina_logan.18.15

Logan C. 2016d. Great-tailed grackle behavioral flexibility and problem solving experiments, Santa Barbara, CA USA 2014-2015. KNB Data Repository. doi:10.5063/F1319SVV https://knb.ecoinformatics.org/\#view/doi:10.5063/F1319SVV

Logan CJ, Harvey B, Schlinger BA, Rensel M. 2016. Western scrub-jays do not appear to attend to functionality in Aesop's Fable experiments. PeerJ 4:e1707 doi: $10.7717 /$ peerj. 1707 .

Logan CJ, Jelbert SA, Breen AJ, Gray RD, Taylor AH. 2014. Modifications to the Aesop's Fable paradigm change performances in New Caledonian crows. PLOS ONE 9:e103049 doi:10.1371/journal.pone.0103049

Lynn DA, Brown GR. 2009. The ontogeny of exploratory behavior in male and female adolescent rats (Rattus norvegicus). Developmental Psychobiology 51:513-520. doi:10.1002/dev.20386

Manrique HM, Völter CJ, Call J. 2013. Repeated innovation in great apes. Animal Behaviour 85:195-202 doi:10.1016/j.anbehav.2012.10.026

Montiglio PO, Garant D, Thomas D, Réale D. 2010. Individual variation in temporal activity 639 patterns in open-field tests. Animal Behaviour 80:905-912

640 doi:10.1016/j.anbehav.2010.08.014 
641 Overington SE, Cauchard L, Cote KA, Lefebvre L. 2011. Innovative foraging behaviour in 642 birds: What characterizes an innovator? Behavioural Processes 87:274-285

643 doi:10.1016/j.beproc.2011.06.002

644 Peer BD. 2011. Invasion of the emperor's grackle. Ardeola 58:405-409

645 doi:10.13157/arla.58.2.2011.405

646

647

648

649

650

651

652

653

654

655

656

657

658

659

660

661

662 Statistical Computing, Vienna, Austria. https://www.R-project.org. Accessed 1 Jan 2016.

Raby CR, Alexis DM, Dickinson A, Clayton NS. 2007. Planning for the future by western scrub-jays. Nature 445:919-921 doi:10.1038/nature05575

Seed A, Seddon E, Greene B, Call J. 2012. Chimpanzee 'folk physics': bringing failures into focus. Philosophical Transactions of the Royal Society B 367:2743-2752 doi:10.1098/rstb.2012.0222

Sih A, Del Giudice M. 2012. Linking behavioural syndromes and cognition: a behavioural ecology perspective. Philosophical Transactions of the Royal Society B 367:2762-2772 doi: $10.1098 /$ rstb.2012.0216

Shaw RC, Boogert NJ, Clayton NS, Burns KC. 2015. Wild psychometrics: evidence for 'general' cognitive performance in wild New Zealand robins, Petroica longipes. Animal Behaviour 109:101-111 doi:10.1016/j.anbehav.2015.08.001

Shettleworth SJ. 2010. Cognition, Evolution, and Behavior (2nd ed). Oxford University Press.

Skutch AF. 1954. Life histories of Central American birds: families Fringillidae, Thraupidae, Icteridae, Parulidae and Coerebidae (No. 598.29728 S629). Berkeley, CA: Cooper Ornithological Society. 
663 Sol D, Griffin AS, Bartomeus I. 2012. Consumer and motor innovation in the common myna:

664 the role of motivation and emotional responses. Animal Behaviour 83:179-188

665 doi:10.1016/j.anbehav.2011.10.024

666 Sol D, Lefebvre L. 2000. Behavioural flexibility predicts invasion success in birds introduced to 667 New Zealand. Oikos 90:599-605 doi:10.1034/j.1600- 0706.2000.900317.x

668

669

670

671

672

673

674

675

676

677

678

679

680

Thornton A, Lukas D. 2012. Individual variation in cognitive performance: developmental and evolutionary perspectives. Philosophical Transactions of the Royal Society B 367:27732783 doi: $10.1098 /$ rstb.2012.0214

Verbeek ME, Drent PJ, Wiepkema PR. 1994. Consistent individual differences in early exploratory behaviour of male great tits. Animal Behaviour 48:1113-1121 doi:10.1006/anbe.1994.1344

Wehtje W. 2003. The range expansion of the great-tailed grackle (Quiscalus mexicanus Gmelin) in North America since 1880. Journal of Biogeography 30:1593-1607 doi: 10.1046/j.1365-2699.2003.00970.x

Zimmer C, Boogert NJ, Spencer KA. 2013. Developmental programming: cumulative effects of increased pre-hatching corticosterone levels and post-hatching unpredictable food availability on physiology and behaviour in adulthood. Hormones and Behavior 64:494500 doi: 10.1016/j.yhbeh.2013.07.002 


\section{Table $\mathbf{1}$ (on next page)}

Exploration and risk aversion results

The percentage of time spent in each aviary section, their risk aversion score (percent time spent in the safest sections of the aviary; sections 1-3) and their exploration score (total number of section changes). 
1 Table 1. Exploration and risk aversion results: the percentage of time spent in each aviary

2 section, their risk aversion score (percent time spent in the safest sections of the aviary; sections

3 1-3) and their exploration score (total number of section changes).

\section{Aviary Section}

\begin{tabular}{|c|c|c|c|c|c|c|c|}
\hline Bird & 1 & 2 & 3 & 4 & 5 & $\begin{array}{l}\text { Risk Aversion } \\
\text { Score (\% time in } \\
\text { safe sections) }\end{array}$ & $\begin{array}{l}\text { Exploration Score } \\
\text { (section changes) }\end{array}$ \\
\hline Tequila & 94 & 0.4 & 0.5 & 6 & 0 & 94 & 16 \\
\hline Margarita & 96 & 0 & 0.1 & 4 & 0 & 96 & 5 \\
\hline Cerveza & 95 & 3 & 0 & 2 & 0 & 98 & 8 \\
\hline Michelada & 92 & 0.06 & 0 & 6 & 2 & 92 & 19 \\
\hline Horchata & 47 & 35 & 5 & 14 & 0 & 86 & 145 \\
\hline Refresco & 100 & 0 & 0 & 0 & 0 & 100 & 0 \\
\hline Batido & 44 & 0.6 & 0 & 0 & 55 & 45 & 30 \\
\hline Jugo & 73 & 12 & 2 & 3 & 11 & 86 & 163 \\
\hline
\end{tabular}

4 


\section{Table 2 (on next page)}

Neophobia results

Neophobia scores for each novel object and an overall score for each individual. Neophobia score calculations: the latency to land on the table in controls (trials 1 and 3 averaged) minus the latency in the novel object condition (trial 2) for each object type (GoPro camera, stone dropping apparatus, and U-tube apparatus), and summed across object types for the overall neophobia score (positive=less neophobic [bold text], negative=more neophobic). 
1 Table 2. Neophobia scores for each novel object and an overall score for each individual.

2 Neophobia score calculations: the latency to land on the table in controls (trials 1 and 3

3 averaged) minus the latency in the novel object condition (trial 2) for each object type (GoPro

4 camera, stone dropping apparatus, and U-tube apparatus), and summed across object types for

5 the overall neophobia score (positive=less neophobic [bold text], negative $=$ more neophobic).

\begin{tabular}{lrrrr}
\hline & \multicolumn{2}{l}{$\begin{array}{l}\text { Stone } \\
\text { dropping } \\
\text { apparatus }\end{array}$} & U-tube & $\begin{array}{l}\text { Neophobia } \\
\text { score }\end{array}$ \\
\hline Tequila & $\mathbf{7}$ & -444.5 & -156.5 & -594 \\
Margarita & $\mathbf{2 0}$ & 0 & 0 & $\mathbf{2 0}$ \\
Cerveza & -182 & $\mathbf{1 6 7 . 5}$ & -42.5 & -57 \\
Michelada & 0 & 0 & -228 & -228 \\
Horchata & -580 & -1 & -277.5 & -858.5 \\
Refresco & $\mathbf{1}$ & $\mathbf{1 4 8 . 5}$ & $\mathbf{1}$ & $\mathbf{1 5 0 . 5}$ \\
Batido & $\mathbf{1 8 7}$ & -275.5 & -541 & -629.5 \\
Jugo & $\mathbf{3 3 8}$ & -227.5 & -373.5 & -263 \\
\hline
\end{tabular}

6 


\section{Table 3(on next page)}

Motor diversity ethogram

Description of motor actions used while presented with a stick tool use task (techniques 1, 2, 4, 5, 13 and 14 are from Griffin \& Diquelou (2015) who refer to 'gape' as 'lever'). 
1 Table 3. Description of motor actions used while presented with a stick tool use task (techniques

$21,2,4,5,13$ and 14 are from Griffin \& Diquelou 2015 who refer to 'gape' as 'lever').

\begin{tabular}{|c|c|c|}
\hline Technique & Description & $\begin{array}{l}\text { Body } \\
\text { part }\end{array}$ \\
\hline 1. Vertical peck & $\begin{array}{l}\text { Pecks vertically to the horizontal surface of the apparatus } \\
\text { with beak open or closed }\end{array}$ & \multirow[t]{14}{*}{ Bill } \\
\hline 2. Horizontal peck & $\begin{array}{l}\text { Pecks horizontally to the vertical edges of the apparatus } \\
\text { with beak open or closed }\end{array}$ & \\
\hline 3. Upside Down Peck & $\begin{array}{l}\text { Pecks horizontally to the vertical edges of the apparatus } \\
\text { while standing on top of the apparatus, thus the head is } \\
\text { upside down }\end{array}$ & \\
\hline 4. Vertical push & $\begin{array}{l}\text { Makes closed beak contact with the horizontal surfaces of } \\
\text { the apparatus and slides beak vertically along the surface }\end{array}$ & \\
\hline 5. Grab apparatus & The apparatus is held between the two mandibles & \\
\hline 6. Grab stick & The stick is held between the two mandibles & \\
\hline 7. Pull stick & The stick is held between the two mandibles and pulled & \\
\hline 8. Push stick & The stick is held between the two mandibles and pushed & \\
\hline 9. Move stick & The stick is moved from inside to outside of the apparatus & \\
\hline 10. Manipulate Stick & Manipulate stick inside apparatus & \\
\hline 11. Carry stick away & $\begin{array}{l}\text { The stick is held in the beak as the bird flies away from the } \\
\text { table }\end{array}$ & \\
\hline 12. Throw stick & The stick is tossed to the side & \\
\hline 13. Gape & $\begin{array}{l}\text { The closed beak is placed under the edge, in an opening, or } \\
\text { on a surface of the apparatus and then opened }\end{array}$ & \\
\hline 14. Gape upside-down & $\begin{array}{l}\text { Same as gape but the head is upside-down (or at least } 45 \\
\text { degrees from complete upside-down position }\end{array}$ & \\
\hline 15. Stand & Stands on top of the apparatus & \multirow{3}{*}{$\begin{array}{l}\text { Feet } \\
\text { (or } \\
\text { bill) }\end{array}$} \\
\hline 16. Step & Places one foot on the apparatus & \\
\hline 17. Tips apparatus & $\begin{array}{l}\text { Tips apparatus over after standing on top and flying off or } \\
\text { by grabbing with bill and pulling over }\end{array}$ & \\
\hline
\end{tabular}




\section{Table 4(on next page)}

Persistence and motor diversity results, and behavioral flexibility scores

Persistence (the total number of times a bird landed on the table, touched the apparatus, or touched the stick), motor diversity (the total number of motor actions used), and behavioral flexibility scores (number of trials to reverse a preference minus the number of trials to initially learn the preference; from Logan 2016a) per bird (- = did not complete this experiment). 
1 Table 4. Persistence (the total number of interactions with the table, apparatus, and stick), motor

2 diversity (the total number of motor actions used), and behavioral flexibility scores (number of

3 trials to reverse a preference minus the number of trials to initially learn the preference; from

4 Logan 2016a) per bird (- = did not complete this experiment).

\begin{tabular}{llrrr}
\hline Bird & Sex & Persistence & Motor diversity & \multicolumn{2}{c}{ Behavioral } \\
flexibility score \\
\hline Tequila & M & 175 & 6 & 70 \\
Margarita & F & 72 & 5 & 70 \\
Cerveza & F & 81 & 2 & 60 \\
Michelada & F & 18 & 1 & 30 \\
Horchata & F & 145 & 8 & 100 \\
Refresco & M & 1114 & 14 & 50 \\
Batido & M & 4047 & 15 & - \\
Jugo & M & 197 & 6 & 40 \\
\hline
\end{tabular}

5 


\section{Figure 1 (on next page)}

\section{Aviary diagram}

The aviary was invisibly sectioned (dotted lines) from least (1) to most risky (4 and 5). The camera was positioned outside a door at the front of the aviary. Food and water bowls were on the ground at the front of the aviary (grey circles) and perches were located in all upper corners (purple lines). 


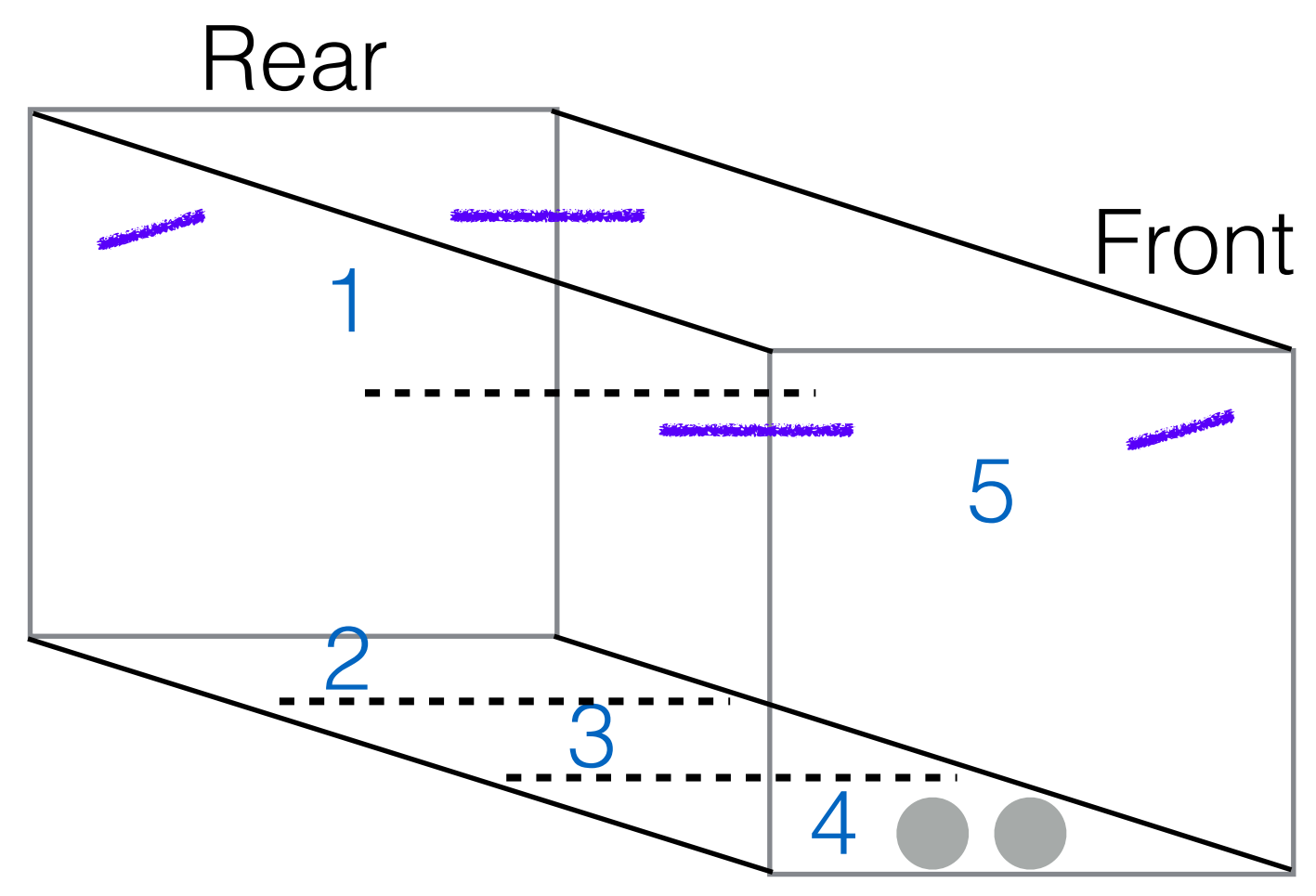


Figure 2 (on next page)

Behavioral flexibility scores in relation to other behaviors

The relationship between behavioral flexibility scores and exploration ( $A$, total number of aviary section changes), risk aversion (B, percentage of time spent in safe aviary sections), persistence ( $C$, total number of interactions with the table, apparatus, and stick), motor diversity ( $D$, total number of different motor actions used), and neophobia ( $E$, latency to land on table during controls minus latency to land next to a novel object) ( $n=7$ grackles). 
